Jernej Habjan

\title{
Sociologija literature in prešernoslovje: nacija od revolucioniranja prek fetišizma do teorije
}

Ključne besede: prešernoslovje, sociologija literature, nacija, ideologija, teorija, bolonjska reforma

Kot ob 30. obletnici Slovenskega sociološkega društva opozori Marko Kerševan (1995, 444-446), so že pred Borisom Ziherlom sociologijo na Slovenskem utemeljevali Andrej Gosar, Aleš Ušeničnik, Janez Evangelist Krek in celo Etbin Costa, za Ziherlom pa Jože Goričar - vendar je prav Ziherl sociologiji dal teoretsko in institucionalno podlago: historični materializem in univerzitetni oddelek.

Danes, ko se bliža 50. obletnica Slovenskega sociološkega društva, je nemara še očitnejše, da sta se po Ziherlu historični materializem in institucija le še oddaljevala. To oddaljevanje pa ni bilo zgolj časovno, temveč predvsem strukturno. ${ }^{1}$ Pogosto je potekalo prav na način institucionalne pozabe Ziherlove dediščine. In nasprotno, Ziherlovo dediščino sta nedavno na historični materializem pozitivno artikulirala teksta, ki zavzemata antiinstitucionalno gledišče. Oba teksta posegata predvsem $\mathrm{v}$ sociologijo literature, ki jo je pri nas prav tako ključno utemeljil Ziherl. Zato si oglejmo najpomembnejšo točko srečevanja sociološke in literarne vede na Slovenskem: prešernoslovje.

\section{Ziherlov medvojni Prešeren}

Ziherlovo pisanje o Prešernu se formira med vojno in v prvem povojnem obdobju. $\mathrm{V}$ obeh primerih bomo to pisanje brali skoz omenjeni nedavni reaktualizaciji Ziherla. $\mathrm{V}$ prvem primeru se bomo navezali na razpravo Miklavža Komelja Kako misliti partizansko umetnost?, v drugem pa na razpravo Rastka Močnika Julija Primic v slovenski književni vedi.

Specifiko Ziherlovega medvojnega Prešerna najlažje prikažemo na ozadju dveh Ziherlu najbližjih sočasnih branj Prešerna, ki sta prav tako dokumentirani

1 Ta paradoksna hkratnost utemeljenosti sociološkega univerzitetnega oddelka na historičnem materializmu in praktične odsotnosti historičnega materializma $\mathrm{z}$ oddelka je izhodiščni problem Močnikove nedavne razprave o historičnem materializmu in sociologiji kulture na Slovenskem (Močnik, 2010, 139). 
in materialistično interpretirani $\mathrm{v}$ Komeljevi študiji. Obe branji razbirata in odpravljata Prešernovo metaforiko. Ta je po prvem branju odpravljena kot realizirana $\mathrm{v}$ narodnoosvobodilnem boju, sočasnem temu branju; po drugem branju pa je zanikana, prebrana nemetaforično. Komelj pokaže, da je resnica obeh branj v njunem nasprotju. Ko prvo branje, ki ga prakticira na primer Matej Bor, ustvari partizanskega Prešerna, ki naj bi že slutil osvoboditev slovenske narodne duše, hkrati romantizira partizanstvo (Komelj, 2009, 305). In za drugo vrsto branja značilna Vidmarjeva zahteva: „Odpasti mora vse, kar je širokim množicam nerazumljivo. [...] Poglejte Puškina! Nobene metaforike. Ali pa Prešerna!« - ta zahteva je negirana v Vidmarjevih javnih obrambah "'svobode umetnosti' proti političnemu dekretiranju « (Komelj, 2009, 218, op. 47). ${ }^{2}$ Ko torej Bor Prešernovo metaforiko zvaja na napoved $\mathrm{NOB}, \mathrm{NOB} \mathrm{v}$ resnici reducira na romantiko, in ko jo Vidmar zanika, v resnici le per negationem ponavlja abstraktnost svoje esteticistične obrambe umetnosti pred politiko.

Če ti branji Prešerna beremo skupaj, kot načina odprave Prešernove metaforike, lahko uvidimo produktivnost Ziherlovega Prešerna. Po Ziherlu je lahko antifašistična pesem na Prešernovi ravni, čeprav - in ne kolikor - je brez metaforike. O taboriščnih sonetih namreč pravi, da bi »[n]atančen kritik estet« v njih videl "pomanjkanje besednega zaklada, ponavljanje istih izrazov, mi pa vidimo za temi stihi Prešernov duh«, ki je piski »kljub vsemu narekoval - lep sonet« (nav. po Komelj, 2009, 138, op. 10). In po Ziherlu lahko Prešernu s stališča narodnoosvobodilnega boja pripišemo ne slutnjo tega boja, ampak - boj proti Novalisovi »reakcionarni romantiki« (nav. po Komelj, 2009, 289, op. 5), boj, ki ga je Prešeren bil v svojem času in v svoji pesniški praksi.

Se pravi, Borov Prešeren je proto-partizan (tako da je partizan le romantik v akciji), Vidmarjev Prešeren pa je proto-socrealist (tako da je socialistični realizem samo romantika brez metafor). Ziherlov Prešeren je, nasprotno, »revolucionarni romantik« (nav. po Komelj, 2009, 289, op. 5), ki se skupaj s Shelleyjem in Byronom bori proti reakcionarnosti same romantične poezije. In prav kolikor je bil Prešeren revolucionaren $\mathrm{v}$ svojem času in $\mathrm{v}$ svoji praksi, je lahko po Ziherlu preusmeritev partizanskih pesnikov k Prešernu »zdrava« (nav. po Komelj, 2009, 467). Še več, celo ko se najbolj približa teoriji odseva, Ziherl ne zapusti pesniške ravni: leta 1944 od pesništva zahteva tendenčnost, ker v samo dejanskost dialektično reflektira tendenco, ki je na ravni progresivne poezije: »Resničnost sama je polna tendence. Treba jo je lepo in zvesto prikazati in bo sama govorila za proletariat. [...] Iz razvojne družbene poti same se mora razbrati tendenca in ne sme se iti po starem obrazcu črno-belo« (nav.

2 V primeru Puškina negacijo razvije tudi Rastko Močnik (2009, 105-107), ki pokaže, da je metafor prosta zaimkovna pesem Ljubil sem vas berljiva zgolj z božjega gledišča. 
po Komelj, 2009, 356, op. 10). Medtem ko tako proletkult kakor fin-de-siècle, se pravi tako medvojni kakor povojni Vidmar, vidita v subjektu substanco, Ziherl heglovsko predpostavlja, da je substanca subjekt, se pravi, da je dejanskost tendenčna.

\section{Ziherlov povojni Prešeren}

Ziherlov medvojni Prešeren je tedaj pesnik in kot tak sovražnik nemške romantike. Ziherlov povojni Prešeren pa je mislec in kot tak zaveznik miselnega sovražnika nemške romantike: Hegla. To se zgodi leta 1949 v referatu »France Prešern - pesnik in mislec« in je povzeto leta 1964 v referatu »Hegel in Prešernov krog «. Ziherl sicer govori o Prešernovi »humanistični in demokratični misli« (Ziherl, 1957, 259-260) tudi leta 1952, ko v članku »Ob Prešernovem dnevu« obračuna tako z ždanovskim kakor s sartrovskim odklonom v sodobni slovenski književnosti, članek pa vpelje s temle dialektičnim obratom historicizma: »[N]a ta [Prešernov] dan ne bi smeli govoriti zgolj o tem, kaj nam je Prešeren dal. Morali bi govoriti tudi o tem, kakšno je naše razmerje do Prešerna, do njegovega duha« (Ziherl, 1957, 257). ${ }^{3}$

Da Ziherl Prešerna bere kot misleca, zato da bi interveniral v sodobno vednost, pa je še očitneje v navedenih referatih iz let 1949 in $1964 .{ }^{4}$ Neargumentiran prehod od obravnave Prešerna h kritiki Prijatelja in siceršnjega levičarstva v sodobni vednosti najlepše zgošča referat iz leta 1949, ki mu je ob omembi Prešernovega epigrama Kar je, beži dodana tale opomba: »Pokojni Ivan Prijatelj se je motil, ko je hotel Prešernovo evolucijo od Hegla preko mladoheglovstva k feuerbachovstvu dokazati prav na temelju dialektike $v$ tem epigramu [...]. Kakor je znano, je bila ena glavnih pomanjkljivosti Feuerbachove filozofije $\mathrm{v}$ tem, da je skupaj s Heglovo idealistično mistiko zavrgel tudi njegovo progresivno dialektično metodo« (Ziherl, 1986, 303, op. ${ }^{\star \star \star \star \star \star}$ ). Prešeren tu Ziherlu služi kot pre-tekst za sodobno marksovsko epistemološko debato: kot izgovor

3 V neki drugi tradiciji humanističnega marksizma je bil leta 1957 tudi sam Hegel prebran z gledišča takšnega obrata: »Zgodovinska priložnost, kakršna je 125. obletnica Heglove smrti, bi lahko koga zavedla k temu, kar imenujemo "počastitev«. Toda ta koncept je postal neuporaben, če je sploh kdaj imel kakšno vrednost. Uveljavlja nesramno mnenje, da lahko že zato, ker imamo dvomljivo srečo, da živimo kasneje, in ker imamo poklicno zanimanje za osebo, o kateri naj bi govorili, suvereno dodelimo mrtvi osebi njeno mesto in se tako nekako dvignemo nad njo. Ta vzvišenost odmeva $v$ gnusnem vprašanju, kaj v Kantu, zdaj pa tudi v Heglu, ima kak pomen za sedanjost [...]. Nikdar pa ni zastavljeno nasprotno vprašanje: kaj pomeni sedanjost, če jo soočimo s Heglom; ali ni nemara um, ki naj bi ga pridobili v času po Heglovem absolutnem umu, dejansko že zdavnaj regrediral v odnosu do tega uma in se prilagodil temu, kar pač obstaja, medtem ko je heglovski um poskušal spraviti breme obstoja v gibanje skoz um, ki je celo v tem, kar obstaja (Adorno, 1974, 9).

4 Na koncu drugega od obeh referatov Ziherl to tudi reflektira, vsaj kar zadeva njegovo branje Prešerna kot progresivnega misleca: »Ko sem prevzel nalogo, da [...] govorim o vplivu Hegla na slovensko poezijo $\mathrm{v}$ prvi polovici 19. stoletja, nisem imel namena spuščati se v filozofske analize posameznih pesmi. Predvsem sem želel podčrtati dejstvo, da je Heglova dialektična misel tudi v slovenski zgodovini [...] učinkovala revolucionarno in idejnim predstavnikom najnaprednejših plasti v slovenskem družbenem življenju dala močno pobudo pri iskanju pravilnih rešitev za probleme, ki jih je to življenje postavilo« (Ziherl, 1965, 194). 
zanjo in hkrati kot njena predloga, o dialektičnosti katere se ne more motiti niti ta, ki se moti o dialektičnosti Feuerbachove filozofije.

\section{Recepcija Ziherlovega Prešerna v prešernoslovju}

Takšna mobilizacija Prešerna dobi leta 1969 nalepko, ki se je odtlej v institucionalnem prešernoslovju ne otrese več - kakor institucionalna pozaba Ziherlove dediščine ne preneha več ločevati tega, kar je ta združil, tj. historičnega materializma in univerzitetnega oddelka. Dušan Pirjevec v eseju »Vprašanje o poeziji « formiranje skupnosti na podlagi literature imenuje "prešernovska struktura «. Ta naj bi zaznamovala stoletje interpretiranja Prešerna, ki naj bi ga dopolnila in odpravila Kosova knjiga Prešernov pesniški razvoj iz leta 1966, ki je po Pirjevcu prva sistematična in neprotislovna študija o Prešernu (Pirjevec, 1978, 55-56). Nasproti "prešernovski strukturi«, ki naj bi Prešerna, izrazito pa tudi še Levstika in Cankarja, brala kot reprezentacijo duha narodovega, Pirjevec v sodobnosti zaznava vznik pesništva kot samozadostne igre, proste ideoloških nalog. Takšna je vsaj prevladujoča, kulturniška recepcija Pirjevca. Ta recepcija kulminira najkasneje leta 1986 v knjigi Dimitrija Rupla Sociologija kulture in umetnosti. Rupel Pirjevčevo zavrnitev marksizma v imenu fenomenologije eksplicira in povrh personificira, ko Ziherla zavrne v imenu Vidmarja (Rupel, 1986, 41-51) in samega Pirjevca (Pirjevec, 1978, 97-104). Pirjevec marksizem zavrne kot karizmatični heideggrovski profesor primerjalne književnosti in kot nekdanji partizanski politični komisar, Rupel pa kot konservativni profesor sociologije in prihodnji slovenski zunanji minister. Prvi reproducira jugoslovansko nacionalistično kulturno politiko, drugi postsocialistično slovensko identitetno politiko.

Pirjevec leta 1969 mimogrede omeni Vidmarjevo navedbo, da je predsednik AVNOJA Vladimir Nazor ob listanju žepne izdaje Poezij dejal: »Tale je ustvarila slovenski narod « (Pirjevec, 1978, 56). Ne Vidmar ne Pirjevec izjave ne valorizirata. Tega ne stori niti Rupel, čeprav bi moral le uporabiti že proizveden koncept. ${ }^{5}$ Leta 1981 namreč Rastko Močnik (1981, 36-39) v razpravi Mesčevo zlato v prešernoslovje vpelje koncept Slovenca kot predpostavke teksta o Slovencu. Materializem in heglovsko dialektiko, ki ju Ziherl pripisuje Prešernu kot mislecu, Močnik (1981, 113) locira v Prešernov tekst. Tako je po Boru, Vidmarju, pa tudi Ziherlu naposled mogoča interpretacija Prešernove metaforike. Ta po Močniku nastaja iz sebe, z delom samih

5 Protokoncept lahko z nekaj magnanimitas pripišemo že Ziherlovemu tekstu. Po Ziherlu je Prešeren menil, da je ilirizem neuresničljiv in da bi moral biti ustavljen, če bi se uresničil, in sicer v imenu vzpostavljanja nacionalnega jezika (Ziherl, 1986, 314). Po strukturalni antropologiji lahko zaustavljanju neuresničljivega pripišemo status prepovedi nemogočega, paradigmatski primer katere je seveda prepoved incesta, ki naslovljenca interpelira prav v nacionalni jezik. 
jezikovnih opozicij, ki se odpravljajo tako, da se ponavljajo na višjih ravneh teksta, na katerih razgaljajo svoje lastno delo $\mathrm{z}$ nižjih ravni teksta. To delo se zgosti v Prešernovi metaforiki, ki kot eliptična poziva naslovljenca, da jo dopolni z lastno domačinsko vednostjo, z jezikom, iz katerega se dela sam tekst (Močnik, 1981, 103-106). Ideološki moment ni več v "prešernovski strukturi«, v enosmiselnem branju Prešerna, temveč, nasprotno, v ne-vsej strukturi prešernovskega teksta. Večsmiselnost poezije, ki naj bi bila po Pirjevcu pripoznana po koncu "prešernovske strukture«, je prenesena nazaj v Ziherlovo problematiko poezije in ideologije.

To interpretacijo Močnik nedavno v razpravi Julija Primic v slovenski književni vedi artikulira na kritiko sodobne demontaže nacionalne institucije in na zagovor Ziherlovega Prešerna. Močnik se vrne k Ruplovemu antagonizmu med Ziherlom in Vidmarjem, vendar, kot rečeno, pri tem ne izhaja iz pojma "prešernovska struktura«. Nasprotno, Močnik pokaže, da je Ziherl posegel v prešernoslovje kot vedo, v liberalna in klerikalna branja Krsta, ki so v svoji konjunkciji reproducirala nacionalni kanon (Močnik, 2006, 147-149). Kot poseg v institucijo je torej Ziherlov Krst mogel biti tudi sam pred-teoretski; hkrati pa je moral biti pred-teoretski, saj Ziherl ni imel teoretskih sogovorcev, ki bi ga primorali v dialogični prelom njegovega točkovnega, filozofskega posega v teoretsko prakso (Močnik, 2006, 161-162). ${ }^{6}$

\section{Ziherl brez sogovorca}

Recepcijo Ziherlovega Prešerna lahko torej zajamemo v dveh ekstremih, v Močnikovi Juliji Primic v slovenski književni vedi na eni strani in v slovenski književni vedi na drugi; se pravi knjiga o vedi na eni strani, veda sama na drugi. Gre za ekstrem med pozitivno in negativno recepcijo Ziherla, pri čemer gre oba predikata, pozitivno in negativno, razumeti na ravni izjave in ravni izjavljanja. Močnikova recepcija Ziherla je pozitivna na ravni izjavljanja, kjer dejansko sprejema, tj. obravnava Ziherlovo branje Prešerna, in na ravni izjave, kjer to branje sprejema, tj. kjer ga obravnava kot produktivno. In nasprotno, recepcija Ziherlovega branja Prešerna v slovenski književni vedi je negativna v svojem izjavljanju, kjer tega branja ne sprejema, ne obravnava, kar pomeni, da bi ga tudi v svojih izjavah ne sprejemala, ne obravnavala kot produktivnega.

Ta opozicija med Julijo Primic v slovenski književni vedi in slovensko književno vedo, opozicija med izjavljajočim in izjavljenim sprejemanjem ter izjavljajočim in

6 Tudi ko z Mesčevim zlatom historičnomaterialistična interpretacija Prešerna humanistično problematiko zamenja s teoretsko konceptualizacijo ideološke interpelacije, se prešernoslovje (kolikor ga zastopa Juvanov članek o modernosti Krsta: Juvan, 2002, 357-358) naveže na to konceptualizacijo prek (Žižkovega) točkovnega, filozofskega posega v problematiko interpelacije $\mathrm{v}$ Krstu. 
izjavljenim zavračanjem, pa tudi že naddoloča medsebojno recepcijo Julije Primic $v$ slovenski književni vedi in slovenske književne vede. Tudi tokrat imamo opravka $\mathrm{z}$ opozicijo med pozitivno in negativno recepcijo, a to pot nimamo več na voljo enotnosti med izjavo in izjavljanjem. Močnikova recepcija je namreč pozitivna samo na ravni izjavljanja, kjer dejansko obravnava slovensko književno vedo po Ziherlu, na ravni izjave pa je negativna, saj to vedo obravnava kot epistemološko blokado. Literarnovedna recepcija Močnika pa je negativna na ravni izjavljanja, kjer je recepcija Močnika odsotna, in potemtakem neobstoječa ${ }^{7}$ na ravni izjave.

Močnik torej Ziherla obravnava kot produktivnega, slovensko književno vedo po Ziherlu pa kot neodobravajočo Ziherla - med drugim zato to vedo obravnava kot neproduktivno. Od tod izhaja, da to vedo implicitno obravnava kot neodobravajočo njega samega. Se pravi, propozicija o »Ziherlu brez sogovorca« je implicitna propozicija o »Močniku brez sogovorca«. S tem se seveda postavljamo na pozicijo nekoga, ki zgolj eksplicira povsem jasno implicirano propozicijo. Na splošno je takšna pozicija redundantna, če ne tavtološka. To pa ne velja za našo tukajšnjo pozicijo, saj ta izjavlja prav to, da je Močnik brez sogovorca, tj. brez tistega, ki naj bi prepoznal njegovo implikacijo in nato zavrnil našo eksplikacijo te implikacije kot redundantno ali celo obsceno, idiotsko. Naša eksplikacija torej eksplicira, da eksplicirani tekst ne prepozna sogovorca, a se vendarle naslavlja na nekega naslovljenca. A ta eksplikacija iz tega ne izpelje pragmatičnega paradoksa. Nasprotno, kolikor ločuje med empiričnim sogovorcem in strukturnim naslovljencem ter eksplicirani tekst umešča $\mathrm{v}$ empirično obstoječe prešernoslovje, to prešernoslovje poziva na položaj naslovljenca ekspliciranega teksta. Naša eksplikacija tedaj poskuša slovensko književno vedo prignati do pripoznanja implikacije in s tem do položaja sogovorke Močnikovega in Ziherlovega Prešerna.

\section{Teorija brez univerze}

S tem pa naša eksplikacija le ponavlja strategijo performativne interpelacije naslovljenca na položaj vednosti, strategijo, ki jo Močnik analizira na primeru Nemške ideologije in ki jo danes sam prakticira na primer v kritiki bolonjske reforme univerze, tj. v besedilu, ki »na univerzi ni našlo bralk ne bralcev - kakor njegov pisec tam ni našel sogovorcev ne sogovork« (Močnik, 2009, 535). Navidezni pragmatični paradoks te kritike je v tem, da gre za tekst, ki na univerzo naslavlja teoretsko razvito propozicijo, da univerza ni zmožna sprejeti teorije.

$7 \quad$ Z izjemo literarnokritiških recenzij Jelke Kernev-Štrajn, Mateja Kranjca in Maše Ogrizek ter omembe Julije Primic v slovenski književni vedi v intervjuju Maje Čakarić z Markom Juvanom (Juvan, 2007) in v razpravi Marijana Dovića o t. i. slovenskem kulturnem sindromu (Dović, 2007, 90). Zunaj slovenske literarne vede politično-epistemološki komentar Julije Primic v slovenski književni vedi poda Primož Krašovec (glej Krašovec, 2009). 
Današnjo univerzo Močnik reflektira $\mathrm{v}$ razmerju do bolonjske reforme. V njegovi argumentaciji zoper reformo je mogoče prepoznati simptomatično strukturo freudovskega počenega kotliča: ${ }^{8}$ prvič, podreditev izobraževanja trgu delovne sile, za katero se zavzema bolonjska reforma, je že dejstvo; drugič, nadaljnjega podrejanja univerze trgu bolonjska reforma ne more zagotoviti; in tretjič, univerze sploh ni treba podrediti trgu, saj danes vednost določa tržna gibanja, ne narobe (Močnik, 2009, 418419). To simptomatiko argumentacije lahko legitimiramo, če simptom pripišemo sami referenci argumentacije, tj. če v argumentaciji o bolonji vidimo negativ bolonje: sama bolonja se simptomatično hkrati zavzema za nekaj, kar je že dejstvo, česar sama ne more doseči in česar tudi ni treba doseči. Ta argumentacija je torej negativni model bolonje, model, ki ga pozneje dopolni pozitivna propozicija, da bolonja predvsem preganja teorijo, s tem ko se simptomatično zavzema za nekaj, kar je že doseženo, njej nedosegljivo in hkrati odvečno. Negativni model je torej, rečeno s Freudom, "primer čistega komičnega učinka $\mathrm{z}$ dopuščanjem nezavednega načina mišljenja«, učinka, ki spodbudi pozitivno propozicijo.

Toda ravno kolikor pozitivna teoretska elaboracija začetne argumentacije odpravi simptom na ravni izjave, ta vznikne na ravni izjavljanja. Prav kolikor namreč elaboracija sklene vse tri točke v propoziciji, da reformirana univerza preganja teorijo, se izkaže, da se naslavlja na univerzo, ki prav z gledišča te teoretske elaboracije ni zmožna prepoznati teoretskih elaboracij (pa tudi komične strukture počenega kotliča ne). Raven izjavljanja poglavja o bolonjski reformi univerze predpostavlja naslovljenca, čigar zaprečenost je konceptualno prikazana na ravni izjave.

Simptom z ravni izjave naj bi bil torej odpravljen zgolj kot povzet na ravni izjavljanja: odpravljen-kot-povzet-na-višji-ravni, se pravi aufgehoben v strogo freudovskem branju Hegla. Toda prav na ravni izjavljanja najdemo refleksijo simptoma. Kajti izjavljavec poglavja o bolonizaciji univerze je prakso teoretskega naslavljanja na neobstoječega Drugega že politično valoriziral na primeru Nemške ideologije. Izjavljavec pokaže, da se Nemška ideologija naslavlja na proletariat kot na politični subjekt, nezvedljiv na realno obstoječi delavski razred, in prav s tem naslavljanjem ustvarja prostor za vpis tega subjekta. Kakor torej Nemška ideologija ustvarja kraj, položaj za proletarskega naslovljenca z razredno zavestjo, poglavje o bolonji ustvarja položaj za univerzitetnega naslovljenca s teorijo - in priganja univerzitetnike na ta položaj.

8 »Zgodba o izposojenem kotlu, ki je, potem ko je bil vrnjen lastniku, imel luknjo [...], je izvrsten primer čistega komičnega učinka $z$ dopuščanjem nezavednega načina mišljenja. Izposojevalec se je zagovarjal, da si, prvič, sploh ni sposodil nobenega kotla, drugič, da je bil ta preluknjan že, ko si ga je izposodil, in, tretjič, da ga je vrnil nepoškodovanega, torej brez luknje« (Freud, 2003, 216). 


\section{Literatura}

Adorno, T. W., Drei Studien zu Hegel, Frankfurt ob Majni 1974.

Dović, M., Zgodnje literarne reprezentacije nacionalne zgodovine in »slovenski kulturni sindrom«, Primerjalna književnost [posebna številka] 2007, str. 71-90.

Freud, S., Vic in njegov odnos do nezavednega, Ljubljana 2003.

Kerševan, M., Slovenska sociologija med socialnim okoljem in znanstveno skupnostjo, Teorija in praksa 32, št. 5-6, 1995, str. 444-452.

Juvan, M., Modernost Krsta pri Savici?, v: Romantična pesnitev: Ob 200. obletnici rojstva Franceta Prešerna (ur. Juvan, M.), Ljubljana 2002, str. 347-360.

Juvan, M., Figura, ki povezuje Ljubljančane (vsaj) na trgu, Delo, 13. februar 2007, str. 6.

Komelj, M., Kako misliti partizansko umetnost?, Ljubljana 2009.

Krašovec, P., Rastko Močnik: O muzah, Engelsih in jezikovni politiki, Družboslovne razprave 60, 2009, str. 111-113.

Močnik, R., Mesčevo zlato: Prešeren v označevalcu, Ljubljana 1981.

Močnik, R., Julija Primic v slovenski književni vedi, Ljubljana 2006.

Močnik, R., Spisi iz humanistike, Ljubljana 2009.

Močnik, R., Od historičnega materializma k sociologiji kulture: digresija, deviacija, dubitacija?, v: Včeraj in danes: jubilejni zbornik socioloških razprav ob 50-letnici Oddelka za sociologijo (ur. Vidmar Horvat, K., Lešnik, A.), Ljubljana 2010, str. 137-159.

Pirjevec, D., Vprašanje o poeziji, v: Pirjevec, D., Vprašanje o poeziji; Vprašanje naroda, Maribor 1978, str. 5-86.

Rupel, D., Sociologija kulture in umetnosti, Ljubljana 1986.

Ziherl, B., Književnost in družba, Ljubljana 1957.

Ziherl, B., O humanizmu in socializmu, Ljubljana 1965.

Ziherl, B., France Prešeren - pesnik in mislec, v: Ziherl, B., Zbrana dela. Tretja knjiga (ur. Pagon-Brglez, N.), Ljubljana 1986, str. 294-320. 
Jernej Habjan

\section{Sociology of literature and Prešeren studies: revolutionising, fetishising and theorising the nation}

Keywords: Prešeren studies, sociology of literature, nation, ideology, theory, the Bologna process

In the 1960s, Boris Ziherl provided Slovenian sociology with its theoretical and institutional foundation - historical materialism and a university department. After Ziherl, however, the two have only grown apart, often precisely through institutional ignorance of Ziherl's legacy. And it is by assuming an anti-institutional perspective that two recent studies affirmatively articulate this legacy onto historical materialism. Both texts intervene into the Slovenian sociology of literature, which was also largely founded by Ziherl. I will hence address the key field shared by Slovenian sociology and literary studies: Prešeren studies. Ziherl's account of the Slovenian national poet France Prešeren was formed during WWII and in the postwar period. While Ziherl's interwar Prešeren is a poet and as such an adversary of German Romanticism, his postwar Prešeren is a thinker and as such an ally of Hegel's anti-Romantic thought. In both cases, I will view it against the backdrop of the above-mentioned reactualisations of Ziherl: Miklavž Komelj’s book on Partisan art, for the first period, and Rastko Močnik's book on Prešeren studies, for the second. 